\title{
Analysis of reform on the hierarchical medical system in Xiamen Yangqing Chen
}

\author{
School of Public Health, Xiamen University, Xiamen, Fujian Province, 361000, China \\ angela@cas-harbour.org
}

Keywords: Hierarchical medical system, community health service, health care, Xiamen

\begin{abstract}
The purpose of this study is to discuss the hierarchical medical system in Xiamen. China is now actively exploring to establish a hierarchical medical system. This study discusses the status quo of practice and measures to improve the hierarchical medical system in Xiamen to provide reference for health policy makers and provide experience for other regions to build and improve hierarchical diagnosis and treatment systems.
\end{abstract}

\section{Introduction}

Hierarchical diagnosis and treatment is a fair and efficient mechanism for sharing medical resources through rational allocation of medical resources in different levels of medical institutions and mutual cooperation of medical resources at different levels [1]. Xiamen is one of the first cities in China to build a pilot family doctor system and it has made some headway [2]. Xiamen's hierarchical diagnosis and treatment system relies principally on the community family physician model of "Comanagement of Doctors of Three Kinds" and has achieved good phased results. By literature review, this study analyzed the domestic and international hierarchical medical systems and summarized the hierarchical medical system in Xiamen. Existing problems and improvement methods were also discussed. This study tries to improve the hierarchical medical system in Xiamen to provide reference for health policy makers.

\section{Literature Review}

Xiamen's system of "Co-management of doctors of three kinds" hierarchical diagnosis and treatment of patients has a clear framework of medical management. First, patients with diabetes and hypertension sign up for the network with informed consent and join the "diabetes network" and "hypertension network", respectively. Meanwhile, the patient's medical history is collected and a personal health assessment is conducted. Second, general practitioners and health managers cooperate in the daily management of patients. General practitioners supervise the implementation of treatment plans and make diagnosis and treatment if possible. Health managers are mainly responsible for health education and daily follow-ups. Third, when the patient needs to go to a tertiary hospital for treatment after assessment, the specialist can directly receive inpatient or outpatient treatment. In addition, when general practitioners and health managers believe that a patient's symptoms are not well controlled, worsening or beyond their ability to treat, the general practitioners contact a specialist to transfer the patient to a tertiary hospital. Fourth, if the patient's condition is under control or the symptoms are stable after diagnosis and treatment by a specialist and meets the conditions for referral, the patient will be transferred to the grass-roots community health institution under the jurisdiction of the patient. Under the guidance of the specialist, the general practitioners and health managers will cooperate in the daily management and condition monitoring of the patient [3]. 


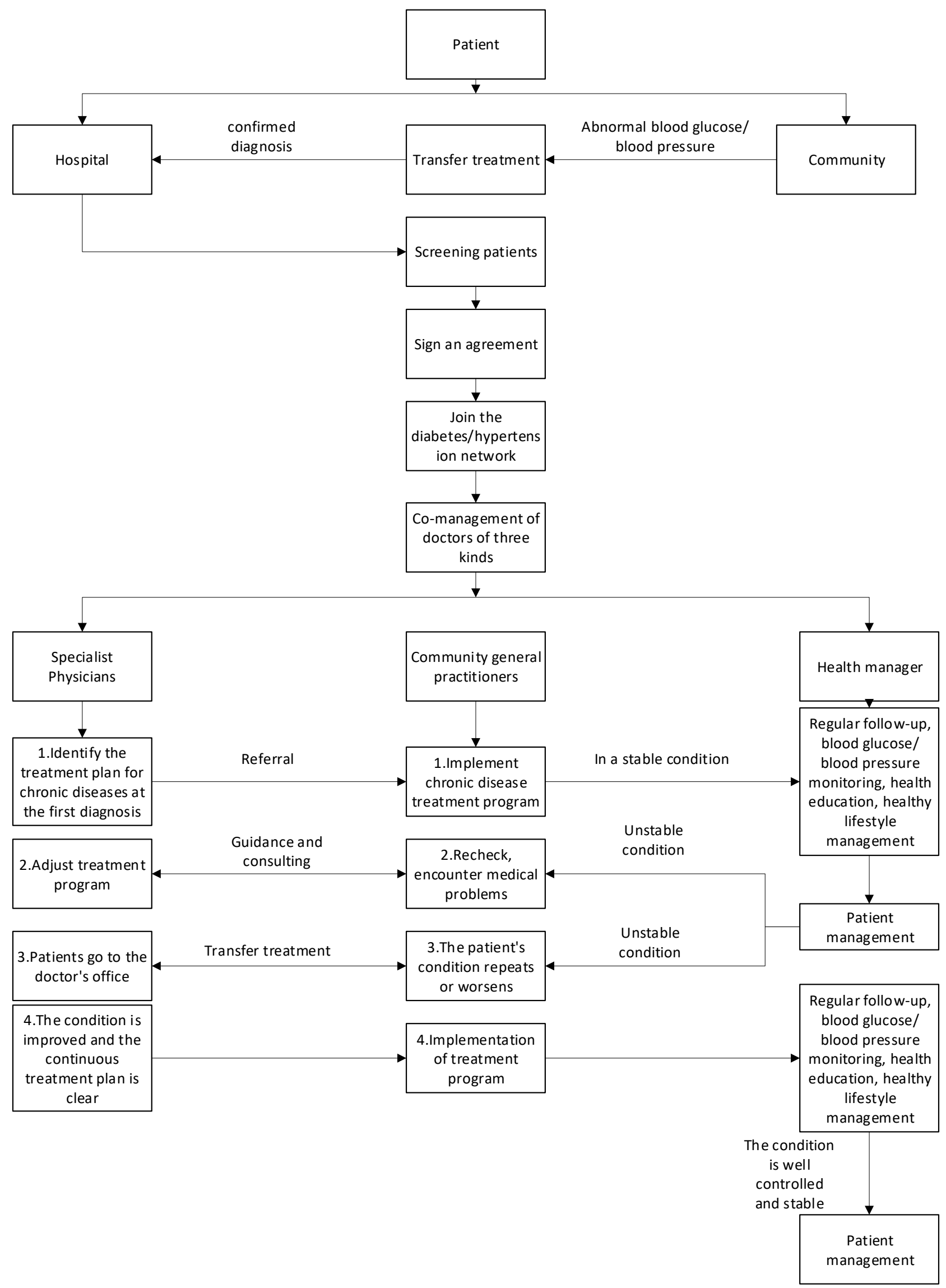

Figure 1 Diagram of "Co-Management of Doctors of Three Kinds" developed in Xiamen[4] 


\section{Analysis}

\subsection{Present Situation of Hierarchical Medical System in Xiamen}

Since Xiamen implemented the "Co - management of Doctors of Three Kinds" mode in the whole city in 2015 , it already has attracted $53.4 \%$ of the residents to choose community hospitals as the first medical institutions. By the end of 2016, there have been 199,000 hypertension patients in the "Comanagement of Doctors of Three Kinds" routine, with standardized management rate of $61.3 \%$; 82,000 diabetic patients were managed, with a standardized management rate of $60.5 \%$, all of which were $20 \%$ higher than before.

Zeng Yanbing's study[5] carried out a cross-sectional survey performed among community residents with T2DM in Xiamen in 2016. This study showed the short-term intervention of "Comanagement of doctors of three kinds" can significantly improve T2DM patients' glucose controlling, and help broadcasting the knowledge of diabetes, self-management, community first diagnosis and two-way referral. It can also significantly decrease the economic burden of disease. Thus the model showed better cost-effectiveness and cost-benefit for diabetes patients. Table 1 shows the result of this study.

Table1 the economic burden of T2DM of the two groups

\begin{tabular}{ccc}
\hline Items & $\begin{array}{c}\text { intervention } \\
\text { (yuan/year) }\end{array}$ & $\begin{array}{c}\text { control } \\
\text { (yuan/year) }\end{array}$ \\
\hline direct economic burden & & \\
outpatient expenditure & 576755 & 421290 \\
hospitalization expenses & 148523 & 552727 \\
total self-purchase cost & 191320 & 236073 \\
transportation costs & 86005 & 157259 \\
nutritional expenses & 331361 & 622161 \\
medical device cost & 124160 & 116820 \\
indirect economic burden & & \\
working hours lost & 43698 & 46263 \\
care services & 16029 & 255455 \\
intangible economic burden & 709927 & 614545 \\
economic burden of diabetes & 2227778 & 2792593 \\
economic burden of disease per capita & 5569 & 6981 \\
\hline
\end{tabular}

The same conclusion was drawn in Chen Fan's study[6]. Chen Fan measured the economic burden of hypertension. She selected five communities randomly from 38 communities in Xiamen. 586 people were in the "Co-management of doctors of three kinds" and 621 were in the conventional chronic disease management group. Table 2 shows the result of this study.

Table2 the economic burden of hypertension of the two groups

\begin{tabular}{ccc}
\hline Items & $\begin{array}{c}\text { Net group } \\
\text { (yuan/year) }\end{array}$ & $\begin{array}{c}\text { Non-net group } \\
\text { (yuan/year) }\end{array}$ \\
\hline direct economic burden & & \\
outpatient expenditure & 363312 & 344034 \\
hospitalization expenses & 226600 & 452002 \\
total self-purchase cost & 151356 & 357834 \\
transportation costs & 62888 & 531808 \\
nutritional expenses & 679760 & 619545 \\
medical device cost & 152632 & 166909 \\
indirect economic burden & & \\
working hours lost & 183568 & 278521 \\
care services & 131640 & 47070 \\
intangible economic burden & 777000 & 771500 \\
economic burden of diabetes & 2728756 & 3569223 \\
economic burden of disease per capita & 4657 & 5748
\end{tabular}

According to the survey of the study [7], the overall satisfaction rate of Xiamen residents to the 
"Co-management of Doctors of Three Kinds" family doctor service was 89.40\% in September 2017. As of the end of 2017, there were 751,800 people signed upthe family doctor service in Xiamen, with the signing coverage rate of $33.97 \%$. Among the key groups, 128,600 people over the age of 65 have signed up for services, with signing rate of $65.35 \%$. From these survey data, it can be seen that since the introduction of family doctor system in Xiamen, the quality of grassroots medical and health services has been greatly improved.

Table 3 satisfaction evaluation of home-signed questionnaires in all districts of Xiamen city in September 2017

\begin{tabular}{ccccccc}
\hline District & satisfaction & No satisfaction & uncertain & $\begin{array}{c}\text { Uncertainty } \\
\text { rate of first } \\
\text { diagnosis }\end{array}$ & $\begin{array}{c}\text { Intention rate of } \\
\text { first visit to } \\
\text { major hospitals }\end{array}$ & $\begin{array}{c}\text { Intention rate } \\
\text { of primary } \\
\text { diagnosis }\end{array}$ \\
\hline $\begin{array}{c}\text { Siming district } \\
\text { Huli district }\end{array}$ & $82.00 \%$ & $3.00 \%$ & $15.00 \%$ & $2.50 \%$ & $14.50 \%$ & $83.00 \%$ \\
$\begin{array}{c}\text { Haicang } \\
\text { district }\end{array}$ & $98.00 \%$ & $2.00 \%$ & $10.00 \%$ & $18.00 \%$ & $10.00 \%$ & $72.00 \%$ \\
Jimei district & $92.50 \%$ & $1.25 \%$ & $1.25 \%$ & $3.75 \%$ & $13.75 \%$ & $82.50 \%$ \\
$\begin{array}{c}\text { Tongan district } \\
\text { Xiangan }\end{array}$ & $89.31 \%$ & $1.26 \%$ & $9.43 \%$ & $6.29 \%$ & $19.50 \%$ & $79.17 \%$ \\
district & $95.83 \%$ & $0.00 \%$ & $4.17 \%$ & $12.50 \%$ & $10.42 \%$ & $77.08 \%$ \\
Total & $89.40 \%$ & $1.46 \%$ & $9.14 \%$ & $8.21 \%$ & $13.51 \%$ & $78.28 \%$ \\
\hline
\end{tabular}

\subsection{Brief summary}

The "Co-management of Doctors of Three Kinds" mode enables general practitioners, specialists, health managers and patients to form a close doctor-patient relationship of benign interaction. It promotes the doctor's effective control of patients' condition, reduces the burden of chronic diseases and improves the management effect.

\section{Discussion}

\subsection{Problems}

First, family doctors are in short supply. At present, Xiamen has an average of 1.53 family doctors per 10,000 residents. According to relevant regulations, the state plans to have more than three family doctors per 10,000 people by 2020, and five family doctors per 10,000 people in Shanghai, Ningbo, Hangzhou and other cities. Compared with the standards of these cities, Xiamen city is in a serious shortage of current supply of family doctors.

Second, the distribution of primary health care resources is uneven. Xiamen now has 25 community health service centers and 13 town health centers. However, the number of grassroots health and medical service institutions has not yet met the needs of the residents. For example, at the end of 2016, the resident population of Siming District and Huli District was 2.01 million, and now there are only 22 community health service outlets (15 centers, 1 sub-center and 6 stations). On average, Xiamen has only one community health service network for every 100,000 residents, while Shenzhen has one social health center (community health service institution) for less than 20,000 people, and Ningbo has one grass-roots medical and health institution for every 51,400 people.

Third, the two-way referral rate is low. Most doctors are given priority to patients with oral reminding, and grassroots hospitals rarely receive referrals from major hospitals. Although the total amount of outpatient and emergency in primary medical institutions continue to increase, but the connection between big hospitals and primary medical institutions is not close, resulting in a low twoway referral rate.

Fourth, residents' willingness to go to community hospitals first is not improved. The data from a questionnaire survey and the third-party agency showed that Xiamen's urban and rural residents have a high awareness rate of hierarchical medical policy[8]. However, the residents distrust the ability of primary medical and health services and their traditional medical treatment habit doesn't change. When there are differences between patients' medical awareness and policy implementation, their medical treatment behaviors will not change, and the government needs to pay attention to this result when formulating policies. 


\subsection{Possible countermeasures}

Firstly, government health administration departments and medical insurance departments should participate together. An active and structured nursing program requires multiparty collaboration, which requires health and family planning bureaus at all levels to strengthen organizational leadership and coordination capabilities, establish a government-led cooperation mechanism with relevant departments, and clarify the responsibilities of each department. For example, development and reform departments should focus on providing medical facilities and equipment for the diagnosis and treatment of primary family doctors. Medical insurance (price) and health and family planning departments should further improve the medical payment policy of family doctor service and determine the price of special services for special groups. The human resources and social security department should adjust the staff structure according to the increase of the manpower demand of the grass-roots medical and health institutions and formulate relevant personnel policies. The administrative departments of traditional Chinese medicine should further improve the basic drug list at the grass-roots level, mobilize the rational use of medical resources conducive to promoting the family doctor system, and the market supervision departments should implement strong supervision of this service according to law. In addition, it is necessary to sum up the practice experience in time for other regions to learn.

Secondly, the government should expand the proportion and number of family doctors, tighten the admission standards, improve the training methods and training mechanism, establish effective assessment and incentive policies, and enhance the occupational attractiveness of family doctors from the institutional level. Moreover, the government should increase the financial investment in the training of medical students, improve the standardized training base for medical students, strengthen the professional ability of general medical students, and attract well-trained medical students to the grass-roots level through generous salaries. At the same time, we need to reform and innovate the system of family doctors' employment, promotion, continuing in-service education and training, and enhance their social status and professional identity.

\subsection{Change the traditional concept and mode of medical treatment}

To realize this goal, all kinds of media tools need to be widely used, such as newspaper, TV, radio, network, mobile APP and so on. At the same time, we should try to form a long-term promoting mechanism by carrying out free medical consultation and health lectures regularly in the community. Xiamen should create a good environment for the whole society to respect and trust family doctors' contract services by setting up advanced models of family doctors.

\section{Conclusion}

Through analysis, this study found that the establishment of a hierarchical diagnosis and treatment model in Xiamen gradually improved the medical service capacity of community health service centers, effectively diverted chronic disease patients in large hospitals, promoted the reasonable distribution of hospital resources, and achieved good initial results. However, this model still needs to be improved, regarding the following problems: short supply of family doctors, unbalanced distribution of primary health care resources, low two-way referral rate, and the local residents' unchanged perception of the new system.

In view of the problems existing in the implementation of hierarchical diagnosis and treatment in Xiamen, this study proposes countermeasures and suggestions from the following aspects: improving safeguards for graded diagnosis and treatment, strengthening vertical communication and collaboration among medical institutions, introducing policies to attract more general practitioners and strengthen the training of them, and carrying out intensive and effective publicity and education.

Although Xiamen's situation is unique, the approach that starts with diabetes and hypertension can be popularized in other regions. Because there is a very large number of patients with diabetes and hypertension in China. Moreover, diabetes and hypertension require long-term management and care, which is a heavy burden. 
But the issue of the sustainability of existing policies, the hysteresis of the personnel system reform should also be paid particular attention in other regions. They should be fully aware that both the strong economic strength and relatively adequate health resources, and a long time exploration and accumulation in the field of social governance would support and pave the way for the hierarchical health care system.

This study also has some limitations as it only analyzed the hierarchical diagnosis and treatment system in Xiamen. Thus, in future studies, it is advisable to analyze medical systems in other places.

\section{References}

[1] X. C. Li, Improvement of General Practitioner's Community First Visit System in the Context of Grading. Medicine and Philosophy (A). 39(11): 49-52, 2018.(In Chinese)

[2] Q. Ma, G. L. Wang, Discussion on Family Doctor System and Countermeasures Based on Models of Shanghai and Xiamen. Medical Contend. 10(03): 72-75, 2019.(In Chinese)

[3] W.S. Liu, Graded diagnosis and treatment Xiamen mode. China Hospital CEO. (In Chinese)

[4] F. Lin, Y. Z. Wu, H. N. Lin, Specialty Physician-general Practitioner-health Manager Management for Members of Diabetes Network and Hypertension Network From Xiamen City, Chinese General Practice, 21(25): 3133-3138,2018.(In Chinese)

[5] Y. B. Ceng, Health Economics Evaluation of the "Co-management of Doctors of Three Kinds" of Diabetes Patients in Xiamen, Journal of Shandong University(Health Sciences), 57(2), 2018.(In Chinese)

[6] F.Chen, The Health Economic Evaluation of "Three-manager Mode" Management for Hypertension in Xiamen, Xiamen University, 2018.(In Chinese)

[7] R. X. Zhu, X. Li, The Construction and Perfecting Countermeasures of Family Doctors' Contracting Service System—Analysis of Xiamen's Experience, Southeast Academic, (06): 64-72, 2018.(In Chinese)

[8] L. Hong, Xiamen City Classification Diagnosis Treatment Practical Situation and Countermeasure Research, Fujian University of Traditional Chinese Medicine, 2018.(In Chinese) 